\title{
THE UK LIDAR-SUNPHOTOMETER OPERATIONAL VOLCANIC ASH MONITORING NETWORK
}

\author{
Mariana Adam $^{1 *}$, Joelle Buxmann ${ }^{1}$, Nigel Freeman ${ }^{1}$, Andrew Horseman $^{1}$, Christopher Salmon $^{1}$, \\ Jacqueline Sugier $^{1}$, Richard Bennett ${ }^{1}$ \\ ${ }^{1}$ The Met Office, United Kingdom, *Email: mariana.adam@metoffice.gov.uk
}

\begin{abstract}
The Met Office completed the deployment of ten lidars (UV Raman and depolarization), each accompanied by a sunphotometer (polarized model), to provide quantitative monitoring of volcanic ash over UK for VAAC London. The lidars provide range corrected signal and volume depolarization ratio in near-real time. The sunphotometers deliver aerosol optical depth, Ångstrom exponent and degree of linear polarization. Case study analyses of Saharan dust events (as a proxy for volcanic ash) are presented.
\end{abstract}

\section{INTRODUCTION}

The Met Office hosts and runs the London Volcanic Ash Advisory Centre (VAAC) as part of nine VAACs worldwide [1]. The VAAC London advisories are based on input from ground-based, satellite-based and aircraft-based observations as well as dispersion models forecast [2]. The ceilometer network is used operationally since 2012 and it produces range corrected signal $(R C S)$ in near-real time (NRT) [1]. The procurement of lidars and sunphotometers started in 2013 and the lidar-sunphotometer network became operational in 2016 (for more details, including the data flow to provide NRT visualization, see [1]). The ultimate goal for the volcanic ash (VA) network is to provide for VAAC the location (altitude of the boundaries) of the VA plumes and estimates of the VA concentrations within the plumes.

\section{LIDAR-SUNPHOTOMETER OPERATIONAL NETWORK}

The Met Office VA Lidar-sunphotometer operational network contains nine fixed locations and a mobile unit (Fig. 1). The lidars (Raymetrics LR111-300) operate in UV and have $\mathrm{N}_{2}$ Raman and depolarization (polar and co-polar) channels. The method used for depolarization calibration for our lidar systems is described elsewhere [3]. The lidars provide $R C S$ and $V D R$ (volume depolarization ratio) in NRT. The sunphotometers (Cimel CE318-NE DPS9) provide the aerosol optical depth $(A O D)$ and Ångstrom exponent $(A E)$ in NRT. The data is also submitted to AERONET [4] with one day delay. In the near future, the degree of linear polarization will be added to NRT products. To assure the eye-safety, the lidars operate at $\sim 50 \mathrm{~mJ} /$ pulse and $20 \mathrm{~Hz}$.

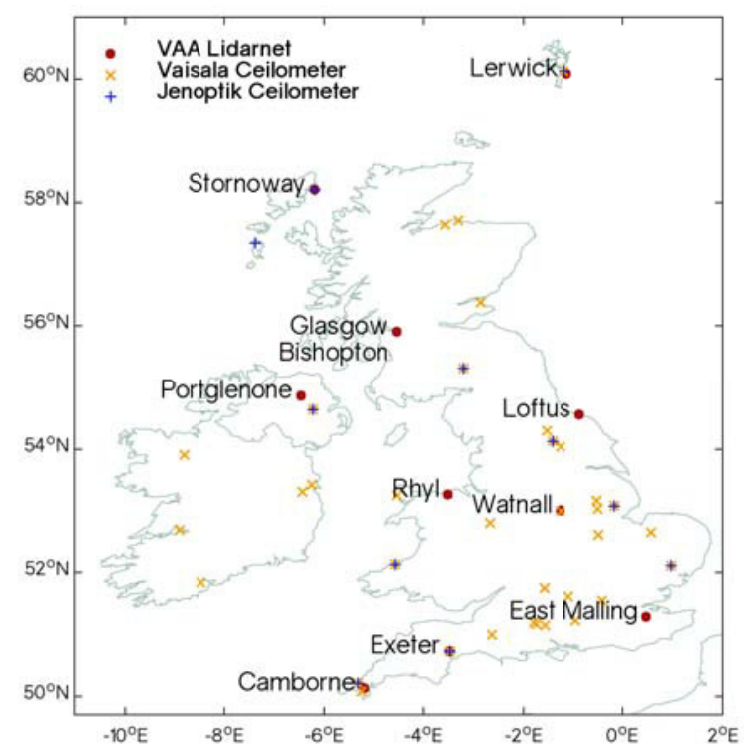

Figure 1.The Met Office Lidar-sunphotometer operational network. Also shown the location of the operational ceilometers.

As a consequence of its geographical location, clouds (i.e. low level clouds or cloud-topped boundary layer) are typically present over the UK. Within these conditions, clear skies or skies with cirrus (Ci) clouds are less frequent.

On the other hand, UK atmosphere is clearer than continental Europe (less pollution). Thus, the network is largely utilized to monitor long-range transport of pollution, such as volcanic ash or Saharan dust clouds.

In the following sections, we describe two events observed by the UK VA network: biomass 
burning event at the end of May 2016; and a volcanic ash event early January 2017 interestingly also associated with buoyancy internal gravity waves.

\subsection{Biomass burning pollution event}

Smoke layers of Canadian forest fires were observed by Lidar systems over centre-Southern UK between $25^{\text {th }}$ and $31^{\text {st }}$ of May 2016 at Exeter, East Malling and Watnall and between $23^{\text {rd }}$ and $31^{\text {st }}$ of May at Camborne. Figure 2 shows $R C S$ and VDR collected at Camborne on May $24^{\text {th }}$, 2016. Note that $V D R$ is shown in $\log 10$ scale to emphasize the depolarization layers.

The pollution event was observed in all four locations at high altitude (between $\sim 5 \mathrm{~km}$ and $\sim 10$ $\mathrm{km})$. On several occasions, the pollution layers coexisted along the $\mathrm{Ci}$ clouds. In the UV region the molecular component of the backscatter signal is important and thus, weak aerosol pollution layers are not always clearly observed in $R C S$ (Fig. 2, upper plot). However, the signature of the non-spherical particles can be seen in VDR (Fig. 2, middle plot). High AOD were also observed (up to 0.45 ), especially between 15:00 and 18:00. In this period $A E$ increases (from 0.5 to 0.9 ), which indicates the relevance of small particles.
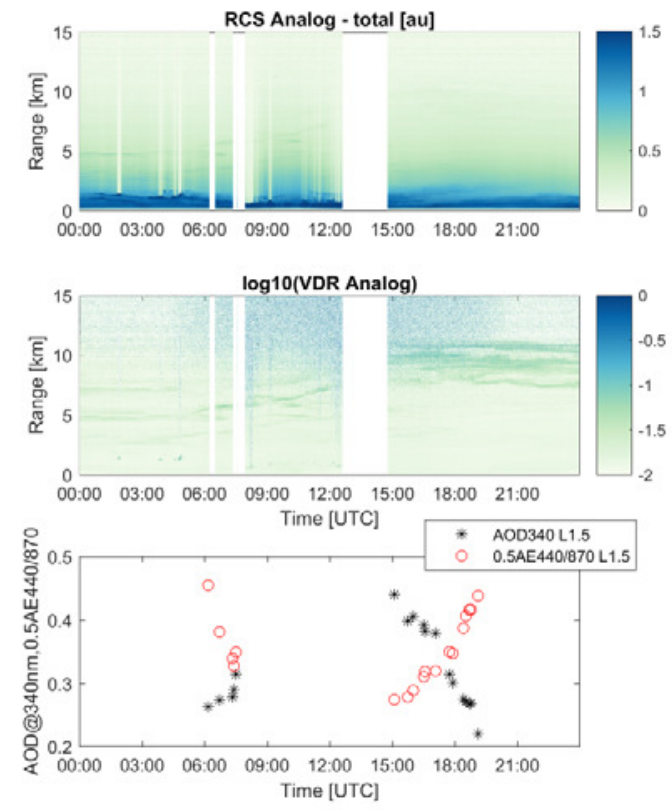

Figure 2. RCS (upper), VDR (middle) and AOD and $A E$ (lower) at Camborne on 24/05/2016 during a biomass burning event.
Consequently, it looks like the contribution of the thin pollution layers is insignificant. On May 26, the pollution layers can still be seen at $8-10 \mathrm{~km}$ at all four locations (Figs. 3-6). No sunphotometer data was available at East Malling and Watnall.
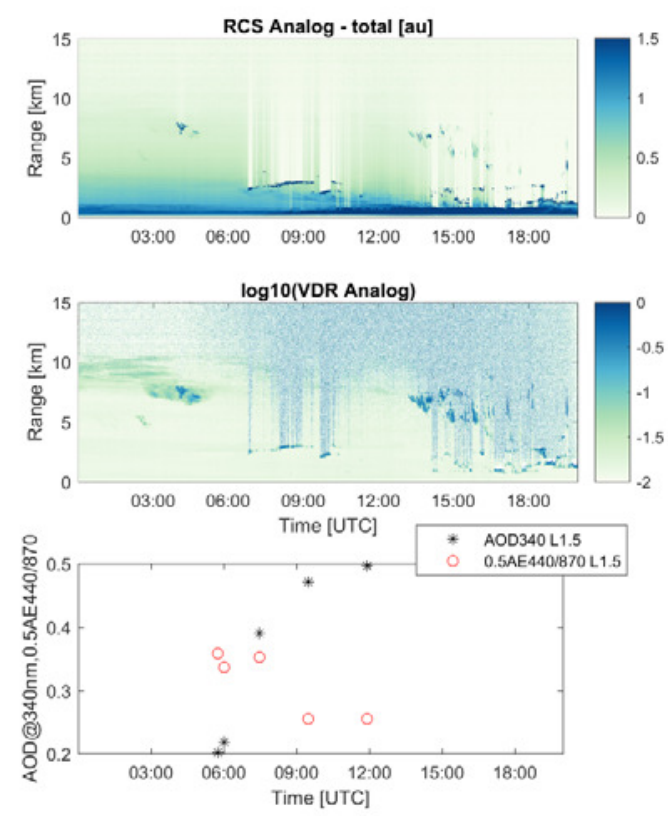

Figure 3. RCS (upper), VDR (middle) and AOD and AE (lower) at Camborne on 26/05/2016 during a biomass burning event.
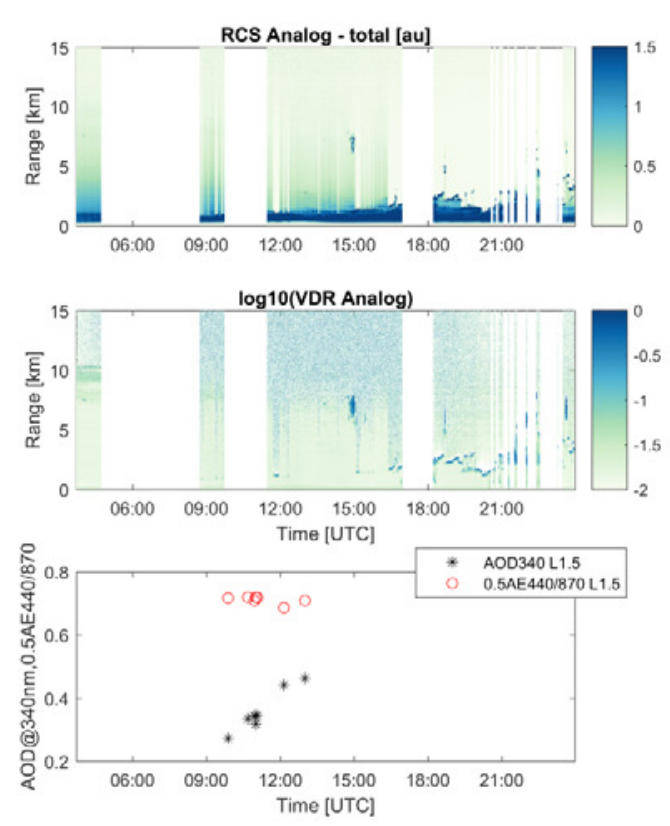

Figure 4. RCS (upper), VDR (middle) and AOD and AE (lower) at Exeter (van) on 26/05/2016 during a biomass burning event 

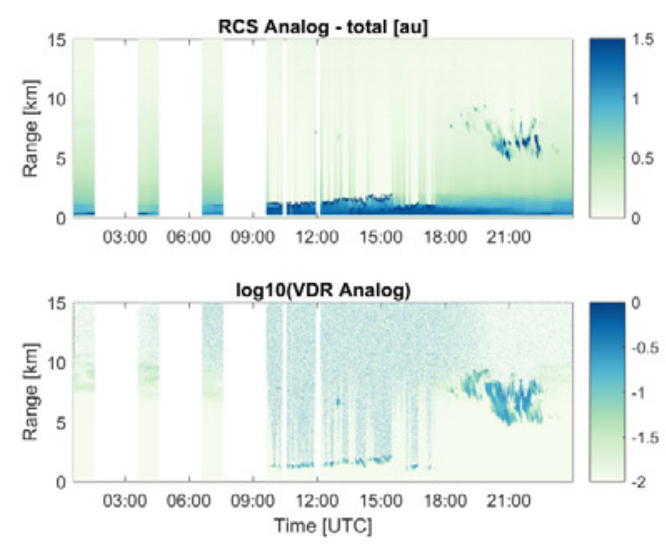

Figure 5. RCS (upper) and VDR (middle) at East Malling on 26/05/2016 during a biomass burning event
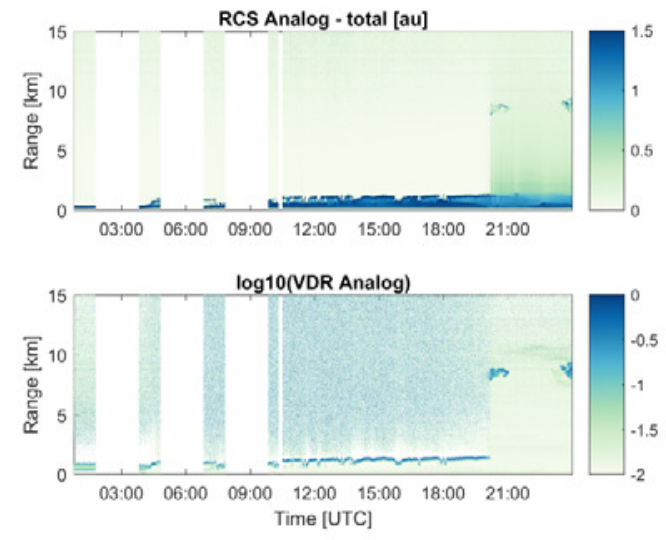

Figure 6. RCS (upper) and VDR (middle) at Watnall on 26/05/2016 during a biomass burning event

For Camborne and Exeter, high $A O D$ values (up to $\sim 0.5$ ) can still be seen but most probably they are due to PBL particles contribution. The full analysis of the particles optical properties will be shown during conference.

\subsection{Buoyancy internal gravity waves}

A weak pollution event took place over central UK towards the end of December 2016 and early January 2017. Preliminary examination suggests that the layer originates from western Alaska and it could have as source the eruption from Bogoslov volcano during December [6]. Continuous measurements were taken at three locations including Glasgow Bishopton in Scotland. On January $3^{\text {rd }}$, a pollution layer is seen descending towards the planetary boundary layer (PBL). On January $4^{\text {th }}$ and $5^{\text {th }}$, a very thin depolarizing layer is noticeable at the top of PBL.
The assumption is that this depolarizing layer originates from the descendent pollution layer. Figures 7 and 8 show $R C S$ and $V D R$ zoomed over first two $\mathrm{km}$ above the ground for January 4 and January 5. The presence of LLC (see Figs 7-8) as
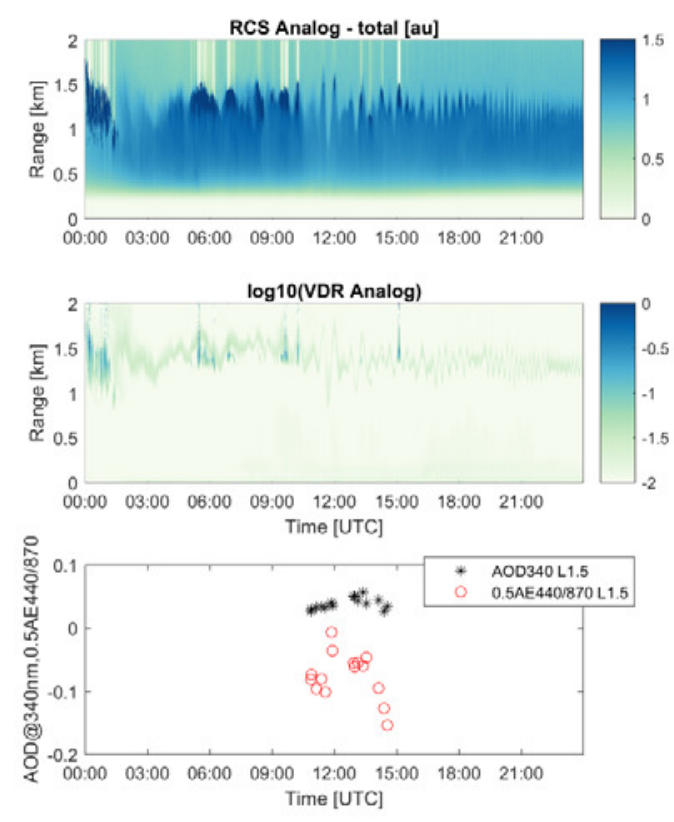

Figure 7. RCS (upper), VDR (middle) and AOD and AE (lower) at Glasgow Bishopton on 04/01/2017after a pollution event. Zoom over [0, 2] km.
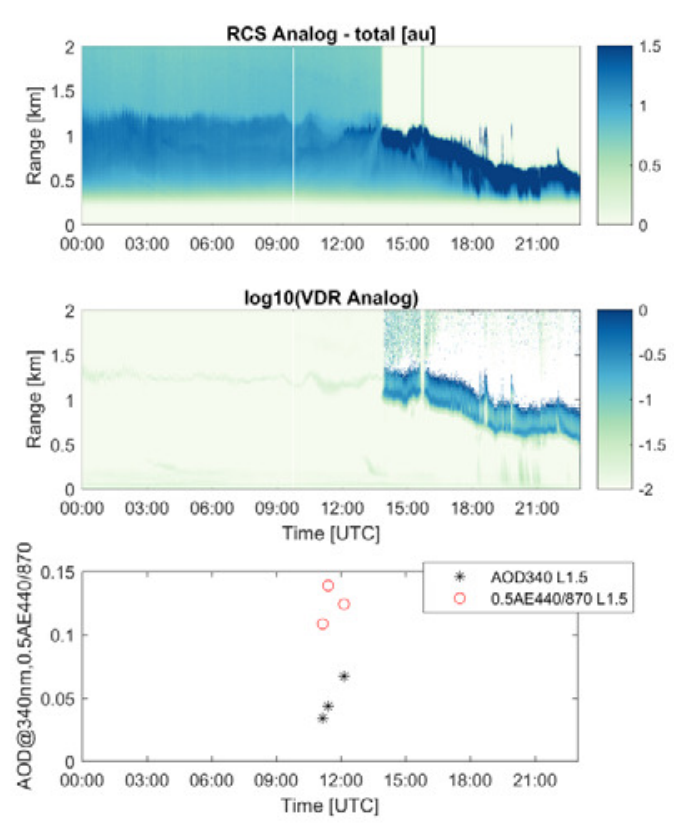

Figure 8. RCS (upper), VDR (middle) and AOD and AE (lower) at Glasgow Bishopton on 05/01/2017after a pollution event. Zoom over [0, 2] km. 
well as of $\mathrm{Ci}$ clouds (from 15:00UTC on 04/01 until 07:00UTC on 05/01) and middle clouds (after $\sim 12: 00 \mathrm{UTC}$ on 05/01) limited the retrieval of $A O D$. Sporadic $A O D$ values show small values (below 0.1 for $340 \mathrm{~nm}$ ). The Met Office NRT for $A O D$ and $A E$ for these days are not in agreement with AERONET [4], for reasons currently unknown. This is under investigation and an update will be given during IRLC.

Figure 9 shows the MSG satellite imagery [5] over Scotland, which confirms the presence of the gravity waves.

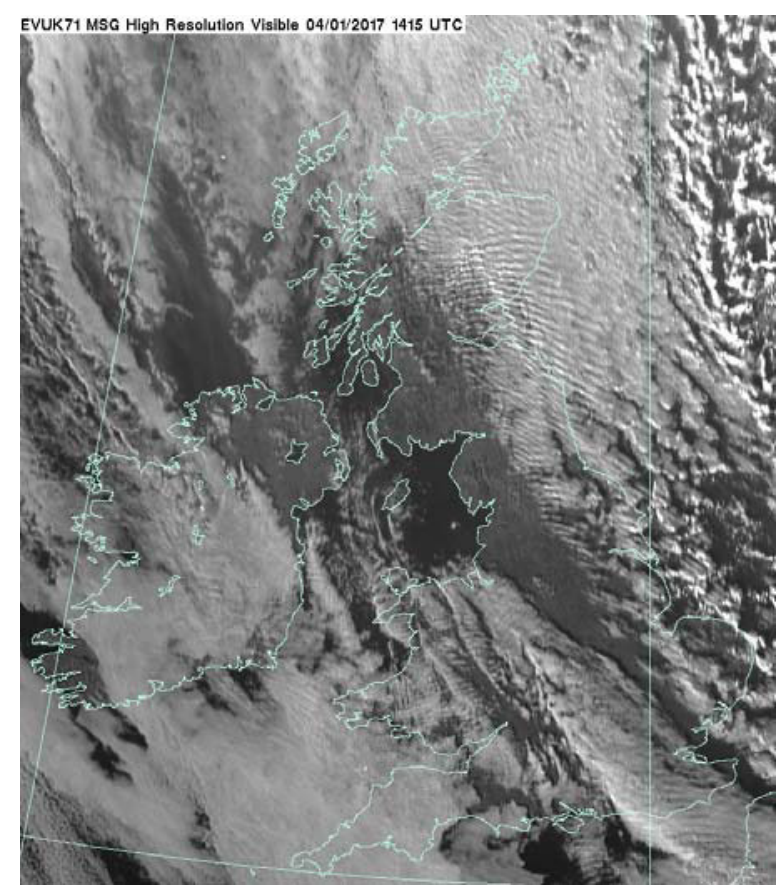

Figure 9. Satellite imagery (MSG) at14:15 on 04/01/2017.

\section{CONCLUSIONS}

An operational network of ten lidars and sunphotometers was successfully set up over the UK by the Met Office in 2016 to monitor volcanic ash. NRT plots with RCS and VDR are used by the VAAC London, along with $A O D$ and $A E$ from sunphotometers. The algorithms to retrieve the particle optical properties are under development

Detailed analysis of the events described here, including the aerosol particles optical properties and optical and microphysical properties as retrieved by AERONET, will be presented at ILRC.

\section{ACKNOWLEDGEMENTS}

We would like to thank all the Met Office teams involved in the VA Lidar-sunphotometer project over the last two years, especially to our engineers' teams. We are grateful to Civil Aviation Authority and Department for Transport for funding this project.

\section{References}

[1] Adam, M., M. Turp, A. Horseman, C. Ordóñez, J. Buxmann, J. Sugier, 2015: From operational ceilometer network to operational Lidar network, proceedings 27 ILRC, S14.06163.

[2] Marenco, F., J. Kent, M. Adam, J. Buxmann, P. Francis, J. Haywood, 2015: Remote Sensing of volcanic ash at the Met Office, proceedings 27 ILRC, PS A4.03-015,

[3] Buxmann, J., Adam, M., Georgoussis, G., Louridas, A., Horseman, A., Sugier, J. 2017: Calibration of the depolarization channel of UV Raman Lidars, proceedings 28 ILRC.

[4]

http://aeronet.gsfc.nasa.gov/new_web/index. html

[5]

http://research.metoffice.gov.uk/research/nw p/satellite/imagery/msg.html

[6] https://watchers.news/2016/12/27/bogoslovvolcano-alaska-december-2016-eruptions/ 